\title{
Producción de trigo en Rusia y la crisis internacional en la economía chilena
}

\author{
Wheat Production in Russia and the international crisis in the Chilean economy
}

\author{
Ernesto Ponce López ${ }^{1}$
}

\begin{abstract}
RESUMEN
La economía chilena se ha visto recientemente afectada por la baja del precio en su principal exportación: cobre. Inicialmente la variación en las bolsas mundiales por la amenaza de cesación de pago de la deuda externa de China, llevó a pensar que esa sería la causa principal de la devaluación del cobre. Pero las reservas de China son enormes y tiene respaldo para pagar sus compromisos. Sin embargo, hay otro aspecto que influye en las bolsas de valores: la integración de la península de Crimea a la Federación Rusa, sumada a una potencial intervención rusa en Ucrania. Los analistas de negocios entienden que al inicio de algún probable conflicto armado, los países tienden a invertir más en almacenar comida que en metales. Esto tendría como motivación principal una anterior mala cosecha de cereales en Rusia, producto de una sequía. Uno de los puntos débiles de la economía de la Federación Rusa es proveer de granos suficientes a una población de 142 millones de habitantes, en tierras que no tienen un clima benigno. El objetivo es destacar la fragilidad de la economía nacional, dependiente de exportaciones de materias primas sin un mínimo de valor agregado, siendo que hubo capacidad para cambiar esta situación y la sigue habiendo en el presente. La metodología se basa en la búsqueda histórica de antecedentes de la influencia del abastecimiento de cereales en la política y economía de las naciones, y en el desarrollo de tecnologías propias para lograr la independencia económica. Se concluye que nuestra economía sigue siendo dependiente y continúa en la misma línea que en los siglos XIX y XX, basada en la exportación de materias primas sin valores agregados y con el agravante actual de un flanco desprotegido, como es la producción de trigo para autoabastecer al país.
\end{abstract}

Palabras clave: producción de cereales, política económica, dependencia tecnológica, tecnologías, cobre.

\begin{abstract}
The Chilean economy has recently been hit by low prices in its main exports: copper. Initially the variation in global Stock Exchange by the threat of default on the external debt of China, led to think that would be the main cause of the devaluation of copper. But China's reserves are huge and have to pay back their commitments. However, there is another aspect that influences the Stock Exchanges: the integration of the Crimea to the Russian Federation, coupled with potential Russian intervention in Ukraine. Business analysts understand that at the beginning of a likely conflict, countries tend to invest more in store food than metals. This would main motivation a previous poor grain harvest in Russia, due to a drought. One of the weaknesses of the economy of the Russian Federation is to provide enough grain to a population of 142 million people in lands that do not have a benign climate. The aim is to highlight the fragility of the national economy, dependent on commodity exports, no additional value-added, being that it was able to change this situation and remain in the present. The methodology is based on the historical background search of the influence of: the supply of cereals in politics and economy of nations, and the development of technologies to achieve economic independence. We conclude that our economy remains dependent and continues in the same line as in the nineteenth and twentieth centuries, based on the export of raw materials without added values and with the current aggravation of an unprotected flank like wheat production to supply the country self.

Key words: cereal, economic policy, technological dependence, technologies, copper.
\end{abstract}

\section{Introducción}

La exportación exclusiva de materias primas en bruto una vez más plantea el delicado equilibrio de nuestra economía: cualquier alteración en los mercados de valores hace oscilar el precio de nuestros productos, en especial el cobre. La ausencia de industrias manufactureras de productos elaborados de este metal favorece a las empresas extranjeras, a las que debemos comprar planchas, barras, tuberías, conductores eléctricos y otros bienes terminados de metales a base de cobre. Es una paradoja volver a comprar a un precio muy superior al que se vende, siendo que en el pasado existían en Chile plantas productoras de estos metales elaborados. En la balanza de pagos, una merma en las divisas significa

\footnotetext{
1 Escuela de Ingeniería Mecánica, Universidad de Tarapacá, Arica-Chile.

* Autor para correspondencia: eponce@uta.cl
}

Fecha de Recepción: 14 Mayo, 2014.

Fecha de Aceptación: 1 Septiembre, 2014. 
que los presupuestos estatales se verán afectados, luego la población sufrirá estos efectos adversos.

En el caso que se analiza, un conflicto limitado puede hacer que el precio de las materias primas ascienda, pero si es una crisis que pueda involucrar a muchas naciones y puede prolongarse, entonces los países intentarán guardar reserva de alimentos y no metales.

Durante la Segunda Guerra Mundial Chile vendió cobre en bruto a los Estados Unidos a un precio ínfimo. Junto con este metal se expedía también a sus cercanos del sistema periódico: plata, oro, platino y selenio, porque estaban mezclados con el cobre y su precio era el mismo que este. Como compensación al término del conflicto nuestro país recibió una planta laminadora de acero de segunda mano y material bélico usado. Paralelamente durante la guerra, Argentina vendía cereales a Estados Unidos, Inglaterra y sus aliados... a un precio de oportunidad. Esto le valió quedar como un país enriquecido y Chile siguió siendo pobre. En la época de postguerra Argentina siguió proveyendo esta vez a toda Europa, con lo que siguió obteniendo grandes ingresos.

En la década de 1980 Chile vendía cobre elaborado por medio de MADECO. Una planta estaba en Santiago y otra existió en Antofagasta. Paralelamente había fundiciones que fabricaban grifería y accesorios de bronce $(\mathrm{Cu}-\mathrm{Sn})$ o latón (CU-Zn), además de barras para bujes. La industria de radiadores también empleaba cobre. Los equipos para una planta de metalurgia de polvos (de apoyo a las automotrices) con sus hornos de atmósfera controlada, prensas, matrices y otras máquinas fueron desembarcadas...y guardadas hasta su remate, con su pérdida Chile perdió la oportunidad de estar a la cabeza en esa tecnología en Sudamérica. Pronto se prefirió comprar fuera que fabricar dentro del país. Los economistas de la época decían que el negocio de Chile era vender cobre en bruto, no venderlo procesado. El tiempo no les concedió la razón. Esta tendencia se continuó aplicando a otras materias primas que se exportan.

Para el momento económico actual, se analiza el efecto que la producción de cereales afecta a las ventas de cobre en el mundo.

La Federación Rusa tiene una producción de granos que alcanza justo para alimentar a su población y a su masa de ganado. En 2012-2013 tuvo una gran sequía seguida de incendios en los cultivos de cereales, se estimó una pérdida de $30 \%$ de los requerimientos nacionales. Fue la sequía más grande en tres décadas. Se vieron en aprietos para cubrir la demanda (Goodrich, 2010). De no haberlo hecho, la situación hubiese sido caótica, porque sus ganados habrían de ser sacrificados, tanto por la falta de alimentos para ellos como para entregar proteínas a la población. Las consecuencias habrían sido malas porque se tarda de 4 a 5 años en reproducir la mermada masa ganadera y se pueden producir alzamientos populares debido al hambre. Ucrania es uno de los principales proveedores de cereales y su principal puerto, Sebastopol, la salida al Mar Negro. La tendencia de algunos nacionalistas ucranianos de acercarse a la Europa Occidental puede ser inaceptable para Rusia. Al salir este país de su área de influencia, Rusia perdería parte de su acceso al Mar Negro, luego al Mediterráneo. Además de perder su principal fuente de alimentos, militarmente quedaría más expuesta al disminuir la distancia entre sus fronteras y sus centros neurálgicos. El tiempo de reacción sería muy pequeño frente a un potencial ataque de misiles por la OTAN.

Es de tal importancia esta zona, que en 1941 Alemania invadió a la Unión Soviética para "ampliar su espacio vital". Esto lo venía anunciando el líder nacionalsocialista, Hitler, desde hacía algunos años en su libro Mi Lucha (Hitler, 1925), ya que el pueblo alemán necesitaría más espacio y alimentos para crecer como él imaginaba. Uno de los primeros países invadidos fue Ucrania, desde donde la producción de cereales durante la ocupación nazi partió rumbo a Alemania. Esto significó un aumento en la crueldad de la guerra, haciendo morir de hambre a millones de habitantes de la URSS que dependían de los granos ucranianos.

Actualmente Rusia produce 100 millones de toneladas anuales de trigo, por política exporta el $20 \%$ a países de Europa del este, Oriente Medio y África (hace algunos años a Cuba).

Rusia no posee una buena infraestructura para almacenar ni transportar granos, salvo el ferrocarril Transiberiano, que conecta su parte europea con su Lejano Oriente. Hay algunas redes para transportar cereales hacia el Mar Negro, que operan el 50\% de las exportaciones rusas. También se han construido depósitos en los Urales y Kazajtán, en la frontera rusa.

La Federación Rusa es precavida al momento de asegurar los suministros y estabilidad de precios en sus países federados, porque puede producirse una inmediata inestabilidad social y política, como ha ocurrido en el pasado. Esta política se basa en que 
su principal alimento son los cereales, que son poco perecederos y se pueden almacenar reservas. Esto concuerda con la estrategia económica de empleo de sus recursos de alimentos, como herramienta en la política externa e interna, siendo un elemento vital para la seguridad nacional. El Kremlin es dueño de casi toda la economía de Rusia. El gobierno controla todos los niveles, ya sean políticos, sociales y económicos, lo que da a su gente la seguridad de cubrir sus necesidades básicas de la vida. Por este motivo una crisis de cereales, que involucre la alimentación del pueblo, atenta contra la seguridad interna.

La política exterior del Kremlin incluye la utilización de recursos naturales para proyectar su poder sobre países vecinos. Empezando con los suministros energéticos, subiendo precios o interrumpiendo el suministro. Las exportaciones de granos también conforman una potente herramienta política. Kazajstán produce 21 millones de toneladas de trigo y exportaba la mitad, ha sido presionado para limitar sus exportaciones a Corea del Sur y China, y tuvo que reconsiderar sus contratos con estos países. La Federación Rusa formó un sindicato aduanero del que forman parte a regañadientes sus países federados, pero donde Moscú maneja la situación.

Ucrania no pertenece a esta federación aduanera, pero tiene una producción de 46 millones de toneladas, siendo el productor de trigo mayor del planeta, exportaba unos 23 millones de toneladas. Por presiones de Rusia redujo sus exportaciones a 16 millones en 2010. Si Rusia quiere extender su poder sobre otros países mediante los cereales, debe necesariamente dominar a Ucrania.

Aún durante el gobierno de la ex-Unión de Repúblicas Socialistas Soviéticas hubo carestía de granos y crisis alimentaria durante algunos períodos, que estuvieron cerca de desestabilizar a la URSS (Forsyth, 1979).

El problema se presenta complejo por las inversiones de Occidente en Ucrania, sobre todo de Alemania y el interés de empresarios estadounidenses de realizar negocios, especialmente en el área agrícola.

Mientras dure esta crisis, con el peligro de la extensión del conflicto, pocas naciones estarán preocupadas de invertir en cobre, luego los precios se mantendrían bajos en este metal, las bolsas de valores pueden tender a la estabilidad en general, pero no en metales diferentes del oro, la plata y el platino. Bajo este prisma, la libra de cobre puede seguir bajo los US\$3, lo que obliga a Chile a seguir manteniendo altos los costos de producción. Se había pensado que con la bonanza anterior (cuando la libra alcanzó US\$4) acrecentar los procesos que utilizan agua de mar, bombeándola a cotas elevadas donde se encuentran las explotaciones. También se contaba con desalar el agua para reducir la corrosión en los largos tendidos de tuberías, superiores a 160 $\mathrm{km}$. Se destaca que ya hay algunas explotaciones mineras importantes que emplean agua de mar sin desalar y otras tienen plantas desaladoras de osmosis inversa. También existen iniciativas políticas cuyo objetivo es considerar obligadamente el uso del agua marina en cualquier nuevo proyecto de faena minera (González, 2014). Con ambas medidas los costos de elaboración se reducirían a largo plazo, pero las inversiones necesarias resultarían inviables con los precios de venta actuales. Con este efecto se continuará empleando el agua dulce de las fuentes naturales, con gran desmedro de la agricultura local.

Los precios de los cereales tenderán al alza. Chile deberá realizar mayores gastos porque importa el 50\% de su consumo. Tiene como proveedores a Argentina, Canadá y USA. Lo paradojal es que a partir del siglo XVI fue un exportador de granos al Perú, esto duró hasta la Independencia. Pero en el siglo XIX exportaba trigo a Estados Unidos (California) y a Australia. Actualmente hay una reducción de la superficie donde antes se cultivaba trigo, ahora muchas de esas tierras se dedican a la producción forestal, dedicándose solo 556.184 hectáreas a producir granos.

Aunque existen más factores que pueden influir en el precio del cobre, como la políticas de los bancos centrales de países ricos; fluctuaciones por especulaciones en las principales bolsas de valores; accidentes y/o huelgas en explotaciones mineras; políticas nacionales de protección, entre otros, se ha remarcado el efecto de una potencial guerra en Europa.

\section{Metodología}

Se realiza un análisis histórico, militar, político, de las características personales del Primer Ministro ruso Vladimir Putin, de la producción mundial de trigo, de la superficie para cultivos de grano, a fin de tener a la vista todos los elementos de juicio de este estudio.

\section{Análisis histórico}

Para una mejor comprensión de lo que acontece actualmente con la producción de cereales y su 
influencia en la economía y mercados internacionales, se realiza una resumida revisión histórica de la zona en conflicto. Desde hace centurias el territorio de Ucrania es disputado, porque es una zona importante de producción de granos en Europa. Se generan invasiones, guerras y cambios de pueblos dominadores, cada cierto tiempo.

Entre los siglos VII a II antes de Cristo los escitas formaron un reino en Ucrania (Boardman, 1992). Durante el siglo VI a. C. hubo colonias griegas, siendo esta región el granero de Grecia (Herodotus, 2003). Posteriormente hubo colonias romanas y luego del Imperio Bizantino, ambas para llevar cereales a sus respectivos pueblos.

En el siglo IV d.C. los godos estaban en la zona, pero cayeron bajo la dominación de los hunos.

En el siglo VII d.C. la parte oriental de Ucrania pertenecía a la Gran Bulgaria, hasta su emigración. Su lugar fue ocupado por los jázaros.

A partir del siglo IX d.C. Ucrania fue ocupada por pueblos eslavos, que formaron el Rus de Kiev, una de las naciones más poderosas de la época, dominación que terminó en el siglo XII de nuestra era. En los siglos XI y XII hubo invasión de tribus turcas que obligaron a los eslavos a huir al Norte (Byrnes, 1994). En el siglo XIII hubo una invasión mongola, que destruyó Kiev y otras ciudades. A partir del siglo XIV parte de Ucrania fue gobernada por Lituania y luego en el siglo XVI hasta el siglo XVII por Polonia.

Guerra ruso-polaca (1605-1618) termina con la toma de Moscú y la derrota de Rusia por parte de Polonia, como consecuencia este último país ocupa Ucrania. Un hecho relevante, ya que ni las tropas alemanas pudieron ocupar Moscú ni derrotar a los rusos durante la Segunda Guerra Mundial. Esto ocurrió debido a las guerras civiles que ocurrían dentro de Rusia. Siglos más tarde, Stalin usó este pretexto como propaganda para atacar a Polonia en 1939.

Los cosacos, tribus nómades provenientes del Dniéper, vivían en Ucrania. Su religión era cristiana ortodoxa. A mediados del siglo XVII los cosacos solicitaron a la Iglesia Ortodoxa de Rusia su protección, lo que más adelante fue causa de la caída del Estado polaco-lituano, que era católica.

Los tártaros de Crimea invadían periódicamente Ucrania, lo que volvía a generar alianzas polacocosacos para controlar estas incursiones. En Crimea habitaban pueblos de origen turco cuya religión era musulmana.
Guerra turco-polaca (1672-1676). Los turcos devuelven Ucrania mediante el tratado de Zorawno (Kohn, 2006).

Gran Guerra Ruso-Turca (1676-1681). Turcos y rusos se reparten Ucrania.

Guerra de la Liga Santa (1699). Rusia, Venecia, Austria contra Turquía. Polonia recupera Ucrania (Black, 1997).

En Crimea se establece el Kanato musulmán, que dura hasta el siglo XVIII.

En el siglo XIX estalla la guerra de Crimea, donde Francia, Inglaterra y Turquía derrotan al Imperio Ruso, que intentaba acercarse al Mediterráneo. En vez de intentar una invasión parecida a la napoleónica, los aliados atacaron el centro neurálgico de Rusia. Crimea ya era valiosa por ser una de las bases más importantes de la flota rusa y tener a Sebastopol como puerta de salida del grano de Ucrania.

Guerra polaco-soviética (1919-1920). 65.000 soldados polacos y 15.000 ucranianos derrotan a las tropas de la Unión Soviética, dentro de ellas se encontraba José Stalin como oficial en jefe de uno de los frentes de batalla. Polonia recupera Ucrania del Oeste, de mayoría católica (Davies, 2005).

Hubo una hambruna en 1921 en Ucrania del Este, durante el período soviético. Luego entre 1932 y 1932 hubo otra peor, muriendo millones de personas y causada por la política llamada como Holodomor. Esto ocurrió por órdenes de Stalin, quien ordenó usurpar las tierras y el ganado de los campesinos, creando granjas colectivas y exigiendo cuotas imposibles de cumplir, quienes se opusieron fueron deportados. También hubo represiones stalinistas en el período 1929-1934 y 1936-1938, con un saldo cercano a 700.000 muertos, incluyendo el $80 \%$ de la élite cultural ucraniana y al $75 \%$ de los oficiales de alta jerarquía en el Ejército Rojo, lo que trajo pésimas consecuencias para la URSS durante la invasión alemana de 1941.

Alemania invadió la URSS en junio de 1941. Hubo una desesperada resistencia en Sebastopol, Kiev y Jarkov. La mayoría de los ucranianos lucharon en el Ejército Rojo o como partisanos contra los nazis. Pero la Organización de Nacionalistas Ucranianos luchó contra los alemanes primero y luego contra el Ejército Rojo, como guerrilleros, aún años después de haber terminado la segunda guerra mundial.

En un comienzo los alemanes fueron recibidos como salvadores por los ucranianos del oeste, recién incorporados en 1939 a la URSS, pero el 
trato brutal de los nazis en el territorio pronto convirtió en enemigos a sus partidarios. El régimen alemán conservó las granjas colectivas, comenzó el genocidio contra los judíos (medio millón asesinados). En total las pérdidas de la población ucraniana durante la ocupación se estiman entre 5 y 8 millones, incluyendo a los judíos. Las pérdidas de soldados ucranianos que lucharon en el Ejército Rojo durante la guerra se calculan en 1,4 millones, de 8,7 millones de soldados muertos de la URSS.

A fines de 1991 Ucrania logra su independencia, el Parlamento firmó la Declaración de Soberanía, que establece los principios de libre determinación, su democracia, su independencia política y económica, con la prioridad de la Ley de Ucrania sobre la Ley Soviética en su territorio.

\section{Análisis militar}

Después de la caída de la URSS, Ucrania heredó un ejército de 800.000 soldados, con un arsenal de armas atómicas mayor en el mundo. En mayo de 1992 firmó el tratado START1 y se comprometió a entregar sus armas nucleares a Rusia, para ser eliminadas. También ha reducido su arsenal en artillería y blindados. En la actualidad posee el ejército más grande en Europa, después de Rusia, alcanzando los 300.000 efectivos. Según las declaraciones de uno de sus políticos, aún posee armas nucleares y la intención de usarlas contra Rusia en caso de ser invadidos (EFE, 2014).

Desde el 2000 Ucrania estaba inclinada hacia la OTAN. En 2002 se firmó el acuerdo OTAN-Ucrania, pero luego se acordó supeditar este tratado a un futuro referéndum nacional.

Actualmente es difícil que Occidente se involucre en una guerra por defender a Ucrania, pese a los intereses económicos y militares que representa un país de sus características. Pero sí se puede generar una guerra civil entre los nacionalistas y los prorrusos, donde sin duda intervendría Moscú en forma directa o indirecta.

\section{Análisis político}

A comienzos de 1992 Ucrania decretó la liberación de precios; se creó una moneda nueva; se licitaron fábricas de material bélico y se crearon incentivos para las inversiones extranjeras.

En mayo de ese año Crimea declaró su independencia, fue inmediatamente objetada por el
Parlamento ucraniano. Crimea anuló la declaración. En junio Rusia anuló el decreto de 1954 donde cedía Crimea a Ucrania y pidió su devolución. El gobierno de Kiev se opuso, concediendo a Crimea la autonomía económica.

En junio de 1993 se ordenó la apropiación de todo el arsenal nuclear de la ex-Unión Soviética desplegado en Ucrania. Con la desintegración de la URSS este país se convirtió en la tercera potencia nuclear del mundo.

En 1993 Ucrania cedió a Rusia parte de su flota del Mar Negro como compensación de la deuda contraída con Moscú por las entregas impagas de petróleo y gas. También Rusia ayudó a desmantelar los 46 misiles intercontinentales SS-24. Ucrania deseaba conservarlos para garantizar su seguridad frente al expansionismo de Moscú.

En 2006 Rusia dejó de suministrar gas a Ucrania debido a que esta no quiso pagar el incremento del precio en $460 \%$. Según Kiev, la medida rusa fue una represalia por los intentos de volverse más independiente de la Federación Rusa y tener una mayor cercanía con la Unión Europea.

Internamente han aparecido tres sectores: las fuerzas prorrusas que pretenden devolver a Ucrania a la órbita de Moscú, los grupos que desean un acercamiento a la UE y la OTAN, y las organizaciones mafiosas cuyo objetivo es mantener la inestabilidad, con la que lucran.

La desestabilización de la zona ocurre en parte a que Occidente ha intentado imponer su influencia sobre algunos países de la ex URSS, sin considerar los intereses rusos. Uno de sus éxitos fue la Revolución Naranja en Ucrania, sin considerar el ascenso de un gobernante antirruso en Georgia. Sin embargo las elecciones ucranianas fueron ganadas por Viktor Yanukovich, que es prorruso. En Georgia todo terminó con la invasión rusa.

El jefe de la sección de política exterior e interna de EE.UU. en el Instituto de Economía Mundial y Relaciones Exteriores, Fiódor Voitolovski, señaló: Hasta que Washington no aprenda a ponerse de acuerdo con Moscú y hallar soluciones de compromiso y un equilibrio de intereses en cada país del espacio postsoviético, los intentos de obrar de acuerdo con la fórmula del "vencedor se lo lleva todo", lo harán fracasar políticamente enfrentándose a situaciones de crisis y conflictos (Kóbzed, 2014).

El Kremlin sigue considerando el territorio de la ex-URSS como un área de interés privilegiado. 
Cualquier intervención en su exzona de dominio la considera peligrosa.

\section{Características del Primer ministro ruso Vladimir Putin}

Siendo el exjefe de la KGB es sin duda un hombre especial, con una formación única. Lo demuestra su habilidad para mantenerse en el poder y establecer alianzas políticas en el interior de Rusia. Al momento de tomar decisiones duras, lo hace sin titubeos: la represión en Chechenia, la toma del control en Georgia, ahora la invasión de Crimea. Conoce muy bien a Occidente, sus dudas y debilidades. Tiene en mente ocupar al menos parte de Ucrania y si lo consigue, la OTAN nada haría por evitarlo. Es un ajedrecista de buen nivel y tiene una gran formación en judo, que lo hace un personaje combativo y capaz de correr riesgos bien calculados.

Planeó la renovación del armamento ruso, que ya cuenta con blindados y aviones superiores a los de la OTAN, el entrenamiento del Ejército es de primer nivel, esto lo convertiría en un duro enemigo en una guerra convencional. Por otra parte Rusia ya no está en bancarrota, como ocurría en tiempos de Gorvachov, sino que se presenta como una potencia emergente. La Federación Rusa es autosustentable, no depende mucho de Occidente.

Putin tiene una tendencia narcisista: se viste de buen gusto con trajes bien cortados y de buena calidad, se fotografía practicando judo con maestros japoneses, en sus vacaciones aparece con el torso desnudo montando a caballo, por mencionar algunas apariciones con esta tendencia. Siendo un hombre de baja estatura para el común de los rusos, ha sabido abrirse camino entre gigantes que no lo asustaron, no se intimida ante nadie. Tiene las cualidades de los hombres de una estatura menor: es perseverante, busca soluciones diferentes a la que buscarían otras personas y tiene una gran confianza en sí mismo. Habría destacado en cualquier grupo social. Se mantiene frío y a diferencia de otros gobernantes, no suele tener exabruptos. Su vida privada la mantiene en reserva. Tiene una forma de pensar estructurada, lo que le concede ventaja por su capacidad de planear correctamente hacia el futuro.

Cabe hacer notar que hizo una seria advertencia al Secretario de Estado Norteamericano, haciéndole ver que si continuaba la política de control de las semillas se estaría creando un conflicto a nivel mundial, remarcando la disminución de la población de abejas en el mundo (Lannes, 2013).

Su frialdad, oportunismo político, determinación y buen conocimiento de la situación, indicarían que no cederá en su presión para integrar Ucrania a Rusia, sin importar el tiempo que le tome. Este breve análisis de su persona sería un indicativo que la crisis en Ucrania seguirá hasta que consiga su anexión a la órbita rusa. Tiene a su favor las herramientas económicas, políticas y militares... más una gran deuda económica de Ucrania. Las piezas de ajedrez ya están desplegadas. Puede actuar dejando que los acontecimientos sigan su curso e intervendría en el momento que considere más ventajoso.

\section{Producción mundial de trigo 2013-2014}

Para tener un panorama de la importancia de Ucrania como productor de trigo en la economía rusa, se analiza la producción estimada para 2014 y la de 2009.

Para el 2014 se estimó que la producción mundial de trigo sería de 709 millones de toneladas. La producción mundial de 2013 fue de 655

Tabla 1. Producción de trigo por país, en toneladas métricas.

\begin{tabular}{crcc}
\hline País & Toneladas & País & Toneladas \\
\hline Unión Europea & 142.886 .000 & Pakistán & 24.000 .000 \\
China & 121.720 .000 & Ucrania & 22.278 .000 \\
India & 93.510 .000 & Turquía & 18.000 .000 \\
Estados Unidos & 57.961 .000 & Irán & 14.500 .000 \\
Otros & 60.837 .000 & Kazajstán & 13.941 .000 \\
Rusia & 52.091 .000 & Argentina & 10.500 .000 \\
Canadá & 37.500 .000 & Egipto & 8.800 .000 \\
Australia & 27.000 .000 & Marruecos & 7.000 .000 \\
\hline
\end{tabular}

Fuente: Producción Mundial Trigo, 2013. 
millones de toneladas (Consejo Internacional de Cereales, 2014).

Ucrania aparece en el lugar número 10, pero su producción en 2009 alcanzó 46.000.000 de toneladas, teniendo el lugar número 5 en el mundo.

\section{Conclusiones}

La crisis en Ucrania se debe a que estratégicamente es un gran productor de granos y Rusia no quiere perder esta fuente de alimentos, ni que esta nación escape de su órbita. Es posible que mientras dure la crisis, el precio del cobre se mantenga a la baja.

Con los precios bajos del metal rojo no será posible continuar mejorando la tecnología para generalizar el empleo de agua de mar en los procesos de explotación. Seguirá el elevado consumo de agua dulce por parte de las empresas, con deterioro de la agricultura local.
Cualquier crisis económica, política y de mercados de valores puede repercutir más violentamente en nuestra economía, que depende solo de la venta de materias primas.

Mientras los gobiernos chilenos no desarrollen una política de vender productos elaborados de cobre, seguirá la dependencia de las fluctuaciones en las bolsas de valores. Es más, mientras no exista una política de un sostenido desarrollo tecnológico, que nos convierta en exportadores de bienes terminados, Chile seguirá dependiendo de las exportaciones de materiales en bruto y comprando en el exterior (actualmente hasta las vacunas se importan).

La agricultura local se ha descuidado al punto que Chile debe comprar el 50\% del trigo a otros países (además de otros cereales). Si se cerraran las fronteras o el canal de Panamá estuviese inoperante, no habrá pan en el país, ni granos para alimentar al ganado.

\section{Literatura Citada}

Black, J.

1977. La Europa del siglo XVIII 1700-1789. Ediciones AKAL, $538 \mathrm{p}$.

Boardman, J.; Edwards, I.; Sollberger, E.; Hammond, N. 1992. The Cambridge Ancient History. Cambridge University Press, $550 \mathrm{p}$.

Byrnes, R.

1994. The Survey Course that Became a Classical Set: Klyuchevskii's Course of the Russian History. The Journal of Modern History, 66 (4): 737-754.

Consejo Internacional de Cereales

2014. www.igc.int/downloads/gmrsummary/gmrsumms.pdf Consultado: 09/04/14.

Davies, N.

2005 White Eagle, Red Star: The Polish-Soviet War 19191920. Ed. Pimlico. England, 320 p.

Dunning, C.

2001. Rusia's First Civil War: The Time of the Troubles and the Founding of the Romanov Dynasty. Pensylvania State EFE University Press, 672 p.

2014. Timoshenko. "Hay que tomar las armas y matar a los malditos rusos". La Voz de Rusia, http://spanish.ruvr.ru/ news/2014_03_25/Timoshenko-Hay-que-tomar-las-armasy-matar-a-los-malditos-rusos-1987/ Consultado: 01/04/14.

Forsyth, F.

1979. La Alternativa del Diablo. Plaza \& Janés S.A., 616 p.
González, M.; Rivas, C.

2014. Panorama Salado. Rev. Que Pasa Minería. Empresa Periodística La Tercera S.A., Santiago, Chile, 1: 57-64.

Goodrich, L.

2010. Drought, Fire and Grain Production in Russia http:// www.globalresearch.ca/drought-fire-and-grain-productionin-russia/20569. Consultado: 08/04/14.

Herodotus, Marincola, J.; De Selincour, A.

2003, The Histories, Revised, Penguin Group, England, 683 p.

Hitler, A.

2003. Primera edición electrónica de Mein Kampf. EherVerlag. 1925, Jusego-Chile, 415 p.

Kóbzed, A.

2014. El peor fracaso de EE.UU. en el espacio postsoviético. La Voz de Rusia, http://spanish.ruvr.ru/2014_03_24/fracasoEEUU-Rusia-espacio-postsovietico/Consultado: 10/04/14.

Kohn, G.

2006. Dictionary of War. Infobase Publishing, 705 p.

Lannes, $\mathrm{X}$.

2013. Rusia advierte a Obama con amenazas de guerra si no desmantela Monsanto, http://www.saludesencial.org/ blog/rusia-advierte-obama-con-amenazas-de-guerra-si-nodesmantela-monsanto/ Consultado: 14/04/14.

Producción Mundial Trigo

Cosecha 2013-2014, http://www.produccionmundialtrigo. com/previous-year.asp Consultado: 02/04/14. 
